In retrospect it is clear that if bleeding continues following femoral-artery puncture pressure must be reapplied over the groin, even though there is no external evidence of continuous haemorrhage at this site.-We are, etc.,

Margaret M. Platts.

B. A. RIDGWAY.

Department of Medicine,
The Royal Hospital,

Sheffield.

\section{Estimation of Haemoglobin}

SIR,-I would like to make one or two comments on your "To-day's Drugs" article on the estimation of haemoglobin (2 January, p. 40). The subject is always of interest and one about which most haematologists have strong personal views.

Haemoglobin estimations fall into two groups, those performed in a laboratory by technical staff and those performed in general practice or in the wards at night by a doctor. The article mentions that cyanmethaemoglobin methods are at present fashionable and later on that the solution has to stand at room temperature for 10 minutes. This delay is its weakness and makes the use of the pigment undesirable in laboratories receiving many specimens.

This laboratory performs about 100 estimations daily, and recently we reached a record of 160 . Oxyhaemoglobin is used as the pigment, and instead of the Autoanalyzer mentioned in your article a semi-automatic procedure is employed. In this procedure both the haemoglobin estimation and whitecell count are performed on the same specimen, no pipettes are needed, and the process takes only 60 seconds. $^{1}$ Experiments being conducted at present suggest that an electronic P.C.V. reading can be added to the procedure without appreciably increasing the time taken.

For use in general practice the article recommends the M.R.C. Grey-wedge Photometer. This instrument, which is accurate, has the disadvantages of being relatively heavy and expensive. Recent trials in this laboratory suggest that the Lovibond haemoglobinometer, using oxyhaemoglobin as the pigment and reading against an $x$-ray screen, is a suitable alternative.- $\mathrm{I}$ am, etc.,

$$
\begin{aligned}
& \text { Department of Haematology, } \\
& \text { Royal Perth Hospital, } \\
& \text { Perth, Western Australia. } \\
& \text { REFERENCE } \\
& \text { "Davis, R. E., and Nicol, D. J., f. clin. Path., } \\
& 1964,17,467 .
\end{aligned}
$$

\section{Training of Surgeons}

SIR,-Mr. C. Naunton Morgan's statement (6 February, p. 380) that essential facilities for aspiring surgeons should be provided by all training posts throughout the country as soon as possible is indeed welcome in view of the new regulations for the F.R.C.S. examination. One can only hope that the College will be more strict in its inspection and approval of these positions in the future, for I am sure that its list of approved appointments would be drastically reduced if all these hospital posts could be inspected now. And if the opinions of the junior staff concerned were elicited, many of the hospitals, which at first sight appear to conform to the standards imposed by the College, would in fact fail to do so.

Despite statements in the medical press to the contrary, only too often junior staff are looked upon as a " pair of hands." In many hospitals the registrar is on call every night except, perhaps, for one evening off a week. $\mathrm{He}$ is considered by his consultant to be well off-" I did not get that even when I was in your position." How can the surgeon in training attend lectures, evening courses, or even settle down to study on his own under these circumstances. For the majority, adequate time off for study is a myth.

How many of these hospitals have a wellstocked library with up-to-date books ? How often do the standard text-books date back to the 1940's, or even earlier, and are more of historical interest than of practical use ? Side by side with these there may be a recent book of limited appeal to the postgraduate student, but in which the consultant has an interest. In the selection of books, the purchase of which is limited by a derisively small amount, the junior staff frequently are not consulted. Surprisingly, many hospitals do not possess a book on operative surgery for even the established surgeon to consult, let alone his juniors. It can be said, however, that even if text-books are not provided journals usually are, even if limited to the British Medical Fournal and the Lancet, but these often have to do the rounds of pharmacist, sister tutor, etc., before finally reaching the junior staff several weeks later.

Teaching on the whole is non-existent unless one attends a definite postgraduate course. This invariably means having unpaid leave of absence for a course of any length, if one is fortunate to be released for as long, say, as three months, because study leave is limited to two weeks per year; and one does not qualify for unemployment benefit. It is no wonder that many married doctors cannot afford to participate. Surgical tutors and regional advisers are a step in the right direction, but more far-reaching proposals are needed to enable the postgraduate student to pursue his studies with the minimum of financial worry.

I have heard many overseas doctors complaining of the lack of postgraduate training in this country and wishing that they had gone to America. All of them come over here to obtain one of our postgraduate qualifications, in addition to getting experience in what they think is one of the leading countries in surgery in the world. The majority return home with the coveted F.R.C.S., but disappointed and disillusioned about the training facilities for advancing their skills. It is probably true to say that quite a large number leave these shores with little addition to their surgical dexterity, and a no greater enhanced theoretical knowledge, gained from text-books, than could have been achieved in their own country.

If we want to continue to attract overseas doctors and our own graduates, too, into our hospitals, we must cease to regard them as general dogs'-bodies to carry out the routine hospital work at a poor salary. Before the new regulations come into force some serious re-thinking regarding the position in the hospital staff structure of the surgeon in training appears to be necessary.-I am, etc.,

$$
\text { Orpington, Kent. } \quad \text { R. F. BolaM. }
$$

\section{Diagnosis of Amphetamine Addiction}

SIR,-The letter by Dr. P. G. M. G. Walker (6 February, p. 384) raises the problem of diagnosis of amphetamine/barbiturate addiction because of the difficulty in determining amphetamine in urine.

For many months we have been using a simple specific method based on gas-liquid chromatography which can be used for the analysis of amphetamine in urine; the details have now been published. ${ }^{1}$ The presence of barbiturates does not interfere with the determination of amphetamine by this method, and amphetamine may be readily distinguished from other sympathomimetic amines. Since gas-liquid chromatography is now an accepted versatile biochemical tool, and an instrument can be maintained in an operative condition for very little cost, the method we use could be applied as a routine analytical procedure. -We are, etc.,

$$
\begin{aligned}
& \text {-We are, etc., } \\
& \text { A. H. BECKETT. } \\
& \text { School of Pharmacy, } \\
& \text { Chelsea College of Science and } \\
& \text { Technology, } \\
& \text { London S.W.3. } \\
& \text { RERERENCE } \\
& \text {. } \quad \text { Beckett, A. H., and Rowland, M., F. Pharm. } \\
& \text { Pharmacol., 1965, 17, 59. }
\end{aligned}
$$

\section{Snuff}

SIR,-I feel that some reply is required to the letter by Mr. P. E. Roland (20 February, p. 524), for I feel he is unaware of some of Mr. Clifford's later contributions to the medi$\mathrm{cal}$ literature regarding nasopharyngeal carcinoma in the native population in Kenya. ${ }^{1}$

A paper by him in the British fournal of Cancer in March 1964 pointed out that the increased incidence of neoplasia at this site was confined to certain specific ethnic groups, living not at the coast but in areas above 2,000 feet in altitudes where the annual rainfall was over 20 inches. At a symposium on this subject in Singapore in August the members came to the conclusion that a contributing factor that could possibly explain this unusual localization of nasopharyngeal carcinoma was that the natives at this altitude lived in small huts without ventilation, and the high incidence of carcinogenic substances in the air they breathed might result in postnasal neoplasia.

Snuff addiction was not common in this particular region and was not a contributing factor.-I am, etc.,

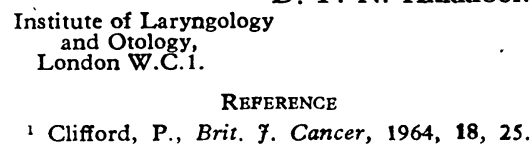

\section{Cheap Purchase of Patented Drugs}

SIR,-In his note on the decision of the House of Lords in Pfizer Corporation v. Ministry of Health (13 February, p. 460), your legal correspondent stated that the House of Lords had held that " the Ministry of Health is entitled to import patented drugs from unlicensed sources for hospitals within the Health Service without making any payment to the patentee." It is true that the House of Lords held, by a majority of three to two, that the Ministry of Health is entitled to import patented drugs from unlicensed sources for use in National Health Service 